\title{
Festa na praia: turismo e sociabilidade juvenil
}

Flávia Alves de Sousa ${ }^{1}$

Resumo: Este trabalho tem como objetivo desenvolver uma reflexão sobre a sociabilidade dos jovens, com base na festa do pisca que acontece na localidade de Flecheiras. Esse distrito litorâneo vem passando por várias mudanças advindas, principalmente, da emergência turística, que dizem respeito tanto à ampliação e reestruturação dos espaços de lazer como às relacionadas aos aspectos sociais, culturais e econômicos. A festa tem um grande número de frequentadores e nos últimos anos tem ampliado a participação dos jovens locais, produzindo experiências diferentes daquelas vividas no cotidiano da localidade.

Palavras chave: juventude, sociabilidade, turismo, mudanças.

Abstract: This work aims to develop a reflection about young people's sociability, based in party of "pisca" that happens on the Flecheiras village, in Trairi town. This beach goes through several changes that arised mainly from the "tourism emergency", which concern both the expansion and restructuring of leisure facilities such as those ones related to social, cultural and economic. The party has a large number of frequenters and in recent years has expanded the participation of local youth, producing experiences different from those lived in the everyday of the locality.

Keywords: young, sociability, tourism, changes

\footnotetext{
1 Graduada em Pedagogia, mestra em Educação pela Universidade Federal de Ceará, atualmente é estudante de doutorado em Sociologia da Educação, no Programa de Pósgraduação em Educação da Universidade de São Paulo - USP, na qual participa do grupo de pesquisa Práticas de Educação de jovens e Adultos, a sociabilidade e a juventude. Email: flaviasousa@usp.br
}

Latitude, vol. 6, n¹, pp.37-50, 2012

DOI: https://doi.org/10.28998/2179-5428.20120104 


\section{Festa na praia: turismo e sociabilidade juvenil}

\section{Introdução}

Neste trabalho pretendo desenvolver algumas reflexões sobre os jovens e suas experiências de sociabilidade na festa do piscaㄹ a qual acontece em Flecheiras, uma pequena localidade do litoral cearense, pertencente ao município de Trairi ${ }^{3}$. Nos últimos anos esse distrito vem passando por várias transformações que são basicamente consequências de dois movimentos: o primeiro corresponde às mudanças que são relevantes na dimensão do contexto nacional e que derivam das condições estruturais, como a expansão da educação nas últimas décadas, as políticas sociais do governo - como bolsa família, ao crescimento da renda familiar e etc. O segundo está relacionado ao cenário atual de grande parte do litoral brasileiro que é expressão da chegada do fenômeno do turismo nas últimas décadas, que tem reestruturado a dinâmica sócio espacial, econômica e cultural de pequenas cidades.

Tem chamado a atenção o grande número de visitantes nessa localidade, sobretudo nas festas de final de ano, momento que são realizadas o Réveillon dos nativos e Amigos de Flecheiras e a Festa do Pisca. Ambas originaram-se em contexto de turismo, acontecem desde a década passada e a cada ano vêm se transformando quanto a sua organização, e proporcionando também novas experiências aos jovens locais.

Dado a particularidade das transformações nessa localidade, penso que algumas vivências são mais intensas que outras, como é o caso das experiências dos jovens nos espaços de lazer em seus momentos de uso do tempo livre. Isso porque, nessas circunstâncias que geralmente acontecem sociabilidades, é que as alteridades se manifestam, onde as vivências interativas com o "outro" se intensificam, as redes de amizade são tecidas e novos valores são compartilhados: "Tem-se definido o lazer como um estado de espírito ou de satisfação consigo mesmo, individualizado ou individualizável. É bem possível, contudo, que o lazer

\footnotetext{
${ }^{2}$ Esse trabalho é parte de uma reflexão maior de minha pesquisa de doutorado que vem sendo desenvolvida sobre os jovens e a sociabilidade no litoral de Flecheiras - em andamento.

${ }^{3}$ Flecheiras é um pequeno distrito que se localiza no litoral Oeste do Ceará, a $140 \mathrm{~km}$ de Fortaleza, região Nordeste do Brasil; tem aproximadamente cinco mil habitantes e pertence ao município de Trairi, o qual possui, segundo dados do IBGE de 2010, 51.432 habitantes. A economia desta localidade, segundo dados da Prefeitura Municipal de Trairi, é baseada no turismo, na pesca, no comércio e na agricultura. O turismo vem configurando aos moradores novas possibilidades de trabalho, através de diferentes ocupações e ofertas de serviços.
} 
venha também assumindo, cada vez mais, uma expressão de sociabilidade. É, pelo menos, o que parece acontecer com os jovens" (Pais, 1994, p. 109). Assim, pode-se dizer que os momentos de sociabilidade estão relacionados à dimensão de lazer, mas não se pode generalizar que toda prática de lazer é produtora de sociabilidade. É importante ressaltar que a sociabilidade relacionada ao lazer adquire uma dimensão particular neste trabalho porque o contexto de pesquisa é um lugar marcado pelo turismo - o que significa dizer que o lazer é bastante valorizado, devido ao maior fluxo de pessoas, maior possibilidades de eventos e festas durante todo o ano. Portanto, não se trata de generalizar que o lazer é uma dimensão importante para os jovens, mas que, nessas localidades turísticas, os momentos de lazer podem explicitar relações complexas entre moradores e turistas.

Os dados de pesquisa aqui apresentados são com base na observação de campo e entrevistas semiestruturada, realizados entre os anos de 2010 e 2012. Este procedimento foi acompanhado do uso de diário de campo, bem como de conversas espontâneas - o que proporcionou uma maior aproximação com os significados destes jovens diante das experiências relativas ao tema abordado. Os interlocutores que contribuíram mais diretamente para essa pesquisa têm entre 18 a 26 anos. A presença no campo de pesquisa me possibilitou desenvolver observações em ocasiões diversas das práticas cotidianas, especialmente das experiências nos momentos de sociabilidade. Os dados correspondem tanto a períodos de férias, isto é, a considerada alta estação, bem como em períodos de baixa estação, o que me propiciou ter uma certa frequência do ritmo de vida desses jovens, das atividades, dos acontecimentos, dos eventos, identificando aqueles que predomina uma organização externa e interna, percebendo os que facilitam uma maior interação entre os jovens locais e desses com os de fora.

Antes de tratar mais particularmente da sociabilidade dos jovens nessa realidade específica faz-se necessário o desenvolvimento de algumas reflexões sobre o litoral em contexto de transformação diante do turismo, que compreende um fenômeno mais recente no litoral brasileiro e mais especificamente no nordeste. As pesquisas têm indicado que as diversas mudanças gestadas com a "emergência turística" implicam diretamente nas condições e modos de vida da população das localidades receptoras.

\section{Flecheiras e a "emergência turística"}

O turismo tem crescido nas últimas décadas no Brasil e ganhado várias proporções. Estamos diante de um momento histórico em que o turismo é considerado como uma atividade econômica com grande potencial desenvolvimentista para o século XXI, principalmente das regiões menos desenvolvidas. No caso do Brasil, destacam-se as regiões costeiras, que tomam a 


\section{Festa na praia: turismo e sociabilidade juvenil}

paisagem como a base do turismo litorâneo, no qual o Nordeste vem se consolidando nos últimos anos, no âmbito nacional e internacional, como um significativo polo turístico.

Inicialmente, o turismo foi ganhando força nas regiões Sul e Sudeste do país, só posteriormente, no final da década de 1980, passa a ser desenvolvido no Nordeste, principalmente com a melhoria das rodovias e ampliação dos aeroportos ${ }^{4}$. Desde então, essa atividade no Nordeste só cresce e tem tomado grandes proporções, tanto em relação à especulação imobiliária, ao crescimento da rede hoteleira, e a criação de serviços pelas agências de turismo. "O Nordeste começa a ser vendido como o novo Caribe, o Novo Mediterrâneo, a Nova Flórida. As iniciativas isoladas dos governos estaduais resultam num significativo aumento dos fluxos, tanto da demanda interna, como da demanda externa" (Rodrigues, 2001, p. 147).

É nesse contexto de expansão das atividades turísticas que Flecheiras, conhecida como uma comunidade pesqueira e calma, na última metade da década de 1990 e o início deste século, passa pela transição de uma localidade com características específicas de vila de pescadores, em que as pessoas viviam basicamente da pesca, da agricultura e do pequeno comércio, para uma localidade como destino turístico. Atualmente, tem sido considerada também por suas belezas naturais, constantemente denominada como um "paraíso turístico", atraindo pessoas com interesses diversos: investidores no ramo da hotelaria, veranistas, turistas, estrangeiros que decidem morar na localidade em busca, principalmente, de paz e tranquilidade, e de pessoas dos municípios vizinhos que também vieram residir, mas só que, diferentemente dos primeiros, estão em busca de trabalho. Esse fenômeno incidiu, portanto, em um movimento migratório nesse pequeno distrito, alterando o cotidiano e redefinindo novas dinâmicas de apropriação do território local. Tornou-se nacionalmente e internacionalmente conhecida por suas belezas paisagísticas, principalmente após a realização do reality show "No limite" (em 2009) da Rede Globo de televisão, que vendia a imagem do lugar como o "paraíso perdido".

Assim, a inserção do turismo provocou significativas mudanças, as possibilidades de trabalho se ampliaram, com hotéis, pousadas, casas de veraneio,

${ }^{4}$ Momento em que os visitantes têm acesso ao litoral Oeste pela estrada conhecida como Rota do Sol Poente ou Estruturante. No final da década de 1990, o Governo do Estado do Ceará desenvolveu uma política de melhoria e construção de estradas que dão acesso ao Litoral Oeste e Leste. Isso faz parte de uma política mais ampla de incentivo ao turismo no Nordeste; em 1991 foi criado o Programa de Ação para o Desenvolvimento do Turismo no Nordeste - PRODETUR-NE. O que veio a beneficiar economicamente os municípios envolvidos, uma vez que se tornaram mais frequentados pelos turistas. Entretanto, vários conflitos foram originados a partir de então, devido à falta de cuidados e planejamentos referentes ao crescimento desordenados e a questão do meio ambiente. 
Flávia Alves de Sousa

condomínios fechados, restaurantes, bares e o aumento significativo do comércio, principalmente supermercados, pequenas lojas de roupas e artesanatos, bem como no ramo da construção civil (tanto com o crescimento dos depósitos de material de construção, como com a necessidade de mão de obra).

Em Flecheiras, algumas transformações no espaço físico que incidem na dinâmica social, datam do ano de 2006, quando foi iniciada uma grande reforma nessa localidade: a rua central que dá acesso à comunidade, que não era asfaltada, agora é de paralelepípedo; à margem esquerda dessa estrada, que dá acesso à praia, foi construído um calçadão; recentemente foram instalados postes de iluminação na parte mais central da praia, propiciando atividades de lazer também à noite, como vôlei, futevôlei e futebol; a igreja católica, que fica ao lado da praça, foi reformada, tendo os seus espaços ampliados; a pequena praça foi totalmente transformada e ampliada, sendo acrescentadas algumas áreas de lazer para as crianças e jovens ${ }^{5}$, bem como quiosques para serem alugados com o objetivo de venda de bebidas e comidas ou artesanatos. Inaugurada no início de 2007, substituiu a pequena praça da TV que era mais frequentada pelos moradores locais do que pelos turistas. O antigo espaço, construído no início da década de 1980, retratava um modelo que lembrava as antigas praças de pequenas cidades do interior, com um suporte para uma televisão e uma pequena arquibancada para a população assistir à programação. Atualmente, é palco de muitos eventos e festas, e um lugar significado de várias formas, de acordo com os interesses dos grupos ou sujeitos que circulam por ela, uma vez que identifico crianças, adultos, jovens e idosos participando de sua dinâmica, tanto os moradores locais como os que estão ali só de passagem.

Em comparação com outros lugares que sofrem com os "efeitos" do turismo desordenado, Flecheiras vem se caracterizando como uma localidade que tenta se organizar para pensar as melhores maneiras de lidar com a inserção do turismo, de forma que seus "efeitos" não impliquem em grandes problemas ambientais e sociais para a população. Nesse sentido, alguns moradores de Flecheiras, de acordo com os seus interesses, organizam-se em associações ${ }^{6}$, com o apoio de outros setores, como da sociedade civil, das Universidades (Federal e Estadual) e

\footnotetext{
${ }^{5}$ Nesta praça foi construída uma pista de skate e brinquedos de madeira para as crianças. Existem divergências quanto à obra, visto que a população não foi consultada quanto ao modelo arquitetônico, pois os jovens dizem que seria muito melhor que fosse uma quadra no lugar da pista de Skate. Logo após a inauguração os jovens começaram a tentar andar de skate, alguns tinham mais sucesso, outros acabavam se machucando muito, acontecendo pequenos acidentes. Atualmente é raro ver alguém andando de skate, mas sim fazendo manobras de bicicleta, ou então correndo de uma ponta a outra, ou mesmo jogando bola.

6 Associações existentes: Associação de Desenvolvimento Comunitário de Flecheiras ADCF; Associação dos Amigos de Flecheiras - AMA; Associação de Produtores de Algas de Flecheiras e Guajiru; Associação de Pousadas e Hotéis de Trairi - Ahtra.
}

Latitude, vol. 6, n¹, pp.37-50, 2012. 


\section{Festa na praia: turismo e sociabilidade juvenil}

Organizações não governamentais, como o Instituto Terramar. Existe também, desde 2005, um Ponto de Cultura ${ }^{7}$ organizado por um grupo de jovens com o apoio e incentivo do Instituto Terramar ${ }^{8}$ e da Associação de Desenvolvimento Comunitário de Flecheiras (ADCF). Atuam principalmente incentivando a dança e o teatro, e contribuindo com os projetos educativos desenvolvidos na comunidade. Uma representante do Instituto Terramar, ressalta que o projeto do Ponto de Cultura foi pensado a partir de atividades artísticas que os jovens já desenvolviam na escola e com o objetivo de sensibilizar e despertar um diálogo entre os participantes, no sentido de discutir direitos e deveres, aprender a lidar com o contexto de sua realidade, de conhecer os efeitos das mudanças que ali acontecem.

Percebo, de uma forma geral, que existe uma organização bastante ativa nessa realidade, e que isso vem contribuindo para pensar o turismo e seus efeitos. De acordo com conversas e entrevistas com jovens participantes da associação e Ponto de Cultura e representantes do Instituto Terramar, é possível considerar que a participação dos jovens é bastante presente, mesmo que isso seja marcada pela rotatividade de alguns membros da ADCF e do Ponto de Cultura, que podem apontar para algumas incompatibilidades entre as práticas coletivas e seus projetos individuais (estudo, cursos, trabalho), mas o que não significa um afastamento total dos projetos e ações coletivas.

Alguns acontecimentos que são paradigmáticos das mudanças e que dinamizam o cotidiano dessa localidade são expressos pelos jovens como os dias de mais movimento, que se caracterizam por uma maior presença de visitantes. Esses dias geralmente correspondem aos períodos de férias, julho $\mathrm{e}$ dezembro/janeiro, sendo que ganham muito mais destaques os períodos de festas, que acontecem em momentos específicos durante todo o ano. Dentre as várias possibilidades festivas, alguns jovens ressaltam aquelas que consideram mais significativas, como o carnaval, a festa do réveillon dos nativos e festa do pisca. Todas essas festas têm marcadamente uma presença de apreciadores externos.

\footnotetext{
${ }^{7}$ Os Pontos de Cultura são entidades apoiadas financeiramente pelo Ministério de Cultura, que desenvolvem ações socioculturais, tem sua gestão compartilhada entre o poder público e as comunidades locais. Não existe um modelo único de atuação, uma vez que isso vai variar de acordo com as necessidades de cada localidade.

8 O Instituto Terramar, fundada em 1993, se designa como uma organização não governamental, sem fins lucrativos, que atua na Zona Costeira do Ceará, visando o desenvolvimento humano com justiça socioambiental, cidadania, participação política, autonomia dos grupos organizados e fortalecimento da identidade cultural dos Povos do Mar do Ceará. Esse instituto tem realizado vários projetos educativos na localidade de Flecheiras, visando o fortalecimento de lideranças e a prevenção das consequências negativas que o turismo pode trazer, como uso de drogas, doenças sexualmente transmissíveis e prostituição infanto-juvenil.
} 
Flávia Alves de Sousa

As festas têm se tornado um atrativo em muitas localidades turísticas. Conforme explicita Rosa, "a festa tem-se revelado como um importante produto da indústria do entretenimento, tornando-se a época de sua realização o momento em que se intensifica a recepção de turistas" (2007, p. 206). Portanto, observar e refletir a partir das experiências de sociabilidades dos jovens nesses momentos de lazer, são análises fundamentais para que se possa compreender as ressignificações e expectativas dos jovens locais diante das transformações turísticas e urbanas produzidas no litoral de Flecheiras.

\section{A sociabilidade dos jovens}

Refletir sobre os processos de sociabilidade é pensar e problematizar a relação entre indivíduo e sociedade. Neste sentido, Simmel é um dos principais pensadores que tem contribuído para o desenvolvimento de leituras interpretativas e analíticas sobre este prisma. Suas reflexões têm como base o contexto da vida urbana moderna e foram suscitadas considerando a seguinte problemática: "como é possível a sociedade?"

Assim, sociabilidade, para este autor, seria uma forma de "sociação", significando os processos mais fluidos e autônomos do fazer e do desfazer das interações, que se manifestam mediante jogos de paquera e conversas sociáveis estabelecidas entre iguais. Sociabilidade é um tipo de interação que tem como principal característica a "ludicidade" nos processos interativos. Diferentemente de outras formas de "sociação", a sociabilidade se autonomiza em relação ao conteúdo, ou seja, dos interesses imediatos, o que está em jogo é a forma ("o estar junto"). Não quer dizer que na sociabilidade o conteúdo não exista, mas ele vai ser secundário no processo interativo. Portanto, o que está em jogo é o modo de se estabelecer a interação, a qual ocorre mais entre iguais, no sentido de que quando existe uma grande hierarquia social fica mais difícil de realizar a sociabilidade, e quando esta hierarquia existe, a sociabilidade que se manifesta é circunstancial.

Neste sentido, os jovens circulam por vários lugares: os institucionais ligados à família, escola, trabalho e espaços menos estruturados da sociabilidade, do tempo livre e do lazer. Nos espaços menos estruturados de sociabilidade os jovens também dinamizam saberes e aprendem sobre a vida de uma forma diferente do que acontece na sala de aula, por exemplo. Pois nesses espaços mais livres que geralmente correspondem ao lazer, o saber não é algo normatizado, sistematizado, nem tão pouco tem objetivos específicos a serem alcançados. Sociabilidade é, portanto, uma dimensão da condição juvenil e se desenvolve nos grupos de pares, considerando os vários espaços, como por exemplo, os de lazer e da diversão.

Em Flecheiras, a vida social dos jovens é demarcada pela diversidade e ambiguidades das experiências por se tratar de um contexto de vivências 


\section{Festa na praia: turismo e sociabilidade juvenil}

específicas em relação aos jovens que vivem nas metrópoles e no meio rural, mas que ao mesmo tempo apresenta um movimento de aproximação/intersecção com essas duas experiências. Entretanto, é importante destacar que as relações sociais são demarcadas frequentemente por um tempo e um espaço diferente daqueles vindos das "grandes cidades".

A dinâmica atual do contexto de estudo produz novas sociabilidades, desde aquelas dinamizadas nos espaços associativos (associação, ponto de cultura), bem como nas que são gestadas nos grupos culturais (grupo de dança, capoeira, quadrilha) e nos novos espaços de lazer, como os encontros na praça, as práticas esportivas que acontecem nos finais de tarde na praia e as festas. Todas essas experiências possibilitam novas produções de subjetividade, implicando nas formas de estar, sentir e conduzir a vida. Essas são formas cotidianas de manifestação de sociabilidade dos jovens desta pequena localidade, mas, neste trabalho, meu objetivo é destacar as sociabilidades que são mediadas nos momentos de festas. Elas correspondem a momentos intensos de interações entre os jovens locais e entre esses e os "de fora". Os períodos de festas dão outra dinâmica ao lugar, que para os jovens significam dias de mais movimento, de possibilidades de conhecerem pessoas diferentes.

Flecheiras é conhecida, principalmente no meio publicitário, por ser uma localidade calma, que oferece aos visitantes a possibilidade de um turismo tranquilo e familiar, diferentemente de outras praias do Ceará, como Canoa Quebrada e Jericoacoara, que são conhecidas por sua beleza e badalação noturna. Isso é sempre ressaltado nos meios de comunicação: "Nesse universo natural (praias de Trairi), o visitante se entrega aos prazeres do lazer tranquilo e respira uma atmosfera de descanso e paz, integrando-se ao cenário" (Caderno de turismo - Jornal Diário do Nordeste, agosto de 2011). Mas o fato é que a imagem de uma vila de pescadores tranquila se transforma de acordo com o movimento de final de semana e as festividades que ocorrem durante o ano e dinamizam o dia a dia dos moradores, principalmente dos jovens, pois aguardam ansiosos esses dias de movimento. As festas tornam-se nessa pequena localidade momentos de lazer, diversão e de encontro com o "outro", com o diverso e diferente, ou seja, essas festas já fazem parte do seu cotidiano, já estão habituados a elas, mas as mesmas não deixam de possibilitar a essa realidade uma certa descontinuidade e excepcionalidade, principalmente no que diz respeito às práticas ordinárias.

Existem algumas festas consideradas tradicionais e singulares em Flecheiras, com o predomínio de participantes do município e de localidades vizinhas, como é o caso da Festa de São Pedro, que ocorre no final do mês de junho e caracteriza-se por representar uma manifestação de matriz religiosa, e que nos últimos anos tem incorporado outros elementos na sua programação. Por outro lado, acontecem festas com a participação de um público externo à região e originadas em contexto de turismo. Nesse caso, darei especial atenção à festa do pisca, caracteriza-se pela 
Flávia Alves de Sousa

presença de apreciadores externos, em sua maioria, jovens, trata-se de um evento em que os elementos centrais aglutinadores de pessoas são música e bebidas alcoólicas. É importante ressaltar essa festa porque representa as mudanças que estão ocorrendo nessa localidade e por significarem momentos de intensas sociabilidades entre os jovens e entre esses e os atores externos.

\section{A festa do Pisca}

A festa do pisca vem se estruturando desde 2005 nessa localidade, organizada majoritariamente por jovens de outros municípios, atualmente acontece em vários dias, iniciando-se após o Natal e se estendendo até o primeiro dia do ano novo, sendo que o seu auge quanto ao número de participantes, é no dia da passagem do ano novo. Isso cria um movimento de circulação entre a festa comemorativa da passagem do ano organizada pelos moradores locais e essa festa do pisca organizada por pessoas de fora.

Esse evento tem em sua matriz organizativa pessoas da capital e de outros interiores. Trata-se de uma festa que tem vários elementos importantes que dão sentido à sua existência: carros com um bom som instalado, músicas diversas, bebidas alcoólicas e nos últimos anos tem marcado forte presença os denominados paredões de sons. Nesse sentido, ao considerar as observações da dinâmica da festa e a ideia de objeto focal, ou seja, o polo de agregação dos participantes, Guarinello (2001), pode-se dizer que, mesmo que ela tenha vários elementos, um deles é fundamental, o som, no sentido mais amplo, as músicas disponibilizadas. É denominada de festa do pisca exatamente porque os jovens se encontram à noite na praia munidos de seu carro com um bom som instalado, deixando o motor do carro ligado com os faróis acesos a piscar, incluindo nessa festa muita bebida. Os carros são organizados de acordo com o gosto musical, mas todos sendo vizinhos. Acontece desta forma uma mistura de sons - ao mesmo tempo se escuta forro, axé, suwingueira, pagode, técnico, funk.

Nos últimos anos, de acordo com a observação que desenvolvi na passagem de ano de 2009 para 2010 e 2011 para 2012, têm destaque os carros que colocam o chamado paredão (é uma montagem de várias caixas de som, muitas vezes acompanhada de jogo de luz e telão) - que acaba por obter o predomínio do som até uma determinada distância. Essa festa foi adquirindo grandes proporções com o aumento do número de carros e consequentemente dos apreciadores, de forma que ela foi sendo deslocada para uma extensão da praia que é menos urbanizada. Participantes dizem que todos os anos eles ficam cada vez mais afastados do perímetro urbano. O afastamento é justificado porque a festa tornou-se um incômodo, especialmente pelo barulho que causava aos moradores das casas de veraneio e à festa organizada pelos residentes para comemorar a passagem de ano, denominada de festa do Réveillon dos nativos. Essa festa acontece desde o início deste século, já é considerada como um dos maiores eventos da localidade, uma vez 


\section{Festa na praia: turismo e sociabilidade juvenil}

que aglomera um maior número de visitantes, principalmente vindos de Fortaleza e de outras regiões do país. A organização é mérito da própria comunidade, através da associação e Ponto de Cultura, com o apoio do Instituto Terramar e da prefeitura do município?.

Atualmente, os limites fronteiriços da festa do pisca são fiscalizados pelos guardas de trânsito do município, pois os frequentadores costumavam não obedecer às fronteiras estabelecidas. De acordo com minhas observações, percebi que a festa não iniciava apenas no período da noite, mas começava muito mais cedo, pois antes do pôr do sol, já era possível ver de longe os carros e ouvir o som, encerrando apenas com o nascer do sol, por volta das sete horas da manhã. A inserção de carros com grandes paredões de som e jogo de luz dificultou mais ainda a possibilidade de se ouvir todos os estilos musicais - que me parece ser o grande objetivo.

A maioria dos participantes é jovem, são frequentadores vindos de vários lugares do estado e da capital, mas com o passar do tempo passou a ser também apreciada pela maioria dos jovens local que se identificam com a proposta. Um jovem destaca os efeitos dessa festa ao comentar sobre o turismo:

Turismo é bom, não é ruim não, tem as festas também de culturas diferentes, como a festa do pisca que eles trouxeram pra gente, que eu nunca vivi e agora estou vivendo! A festa do pisca é uma festa que eu nunca iria saber... A festa é uma coisa muito boa, diferente, que a gente não sabia o que era, e hoje a gente conhece, a gente aproveita, curte. A gente que é jovem quer curtir, aproveitar. Então eles trazem a festa do pisca e a gente curte, se beneficia, dança, faz amizade, conquista pessoas. $\mathrm{O}$ turismo não tem só lado ruim, aprendi muitas coisas e quero aprender cada vez mais... (Gustavo, 22 anos/janeiro de 2010).

Segundo relatos, essa festa do pisca, que iniciou timidamente como uma brincadeira e encontro entre amigos nos períodos de férias, hoje consegue abalar a

\footnotetext{
9 É interessante observar que essa festa foi ganhando proporções inimagináveis pelos organizadores, uma vez que ela se originou a partir da ação de uma moradora participante da Associação, que no ano de 2001 resolveu criar a festa dos "nativos". Um jovem me relata que essa comemoração comunitária originou-se como uma alternativa à festa privada que acontecia em uma casa de veraneio, reservada para quem podia pagar caro, na qual os "nativos" só conseguiam entrar para trabalhar. Com o aumento do turismo na localidade, a festa organizada pela comunidade foi se tornando mais conhecida, a cada ano aumentava o número de participantes. Acontece nas margens da praia, é conhecida por ser uma festa muito bonita e tranquila. A festa teve seu auge quanto ao número de participantes principalmente após a realização do reality show No limite da Rede Globo de Televisão. Desde então, a festa sempre é comentada pelo grande número de participantes, beneficiando os donos de comércio, restaurantes, pousadas e hotéis, bem como os que trabalham com vendas de produtos artesanais e alimentação, pois acreditam ser um ótimo período para os negócios.
} 
dinâmica local, proporcionando dias de muita agitação para os mais jovens, são aproximadamente cinco dias de festa. Dias em que a tranquilidade de uma cidade interiorana se encontra na confluência da intensidade de uma grande cidade, com fluxos de pessoas, imagens e sons. Diferentemente da festa do réveillon dos nativos, que se caracteriza por ter um caráter mais familiar, a festa do pisca possibilita aos jovens locais o deslocamento, o encontro com os diferentes estilos de músicas e de comportamentos, momento de diversão e transgressão, uma vez que estão com seus pares e longe da presença e dos olhos dos pais. Enfim, o instante os conduz a outra esfera diferentemente das regras sociais que compreendem o seu dia a dia. É um movimento de deslocamento do que lhe é comum, mas sem sair fisicamente do local, aproximando, por um lado, das experiências de anonimato próprio dos centros urbanos, uma vez que a grande presença neste espaço é de pessoas desconhecidas e todos compartilhando plenamente da diversão pela diversão, por outro lado, permite a formação de pequenos grupos de conhecidos e amigos, mobilizados pela música e pela bebida, o que não impede a circulação desses jovens por outros grupos. Portanto, mesmo que exista um ponto fixo de encontro do grupo, a festa é demarcada pela circulação desses jovens nos vários sons, sendo que, ultimamente, o som disponibilizado pelos grandes paredões tem agregado mais participantes, sobretudo os jovens que são da localidade. Esse fato é interessante para se pensar na configuração dessa festa, pois por mais que ela se caracterize por ser uma festa aberta, ou seja, participa quem quer, é possível perceber que existem fronteiras simbólicas, não necessariamente impostas, mas espontâneas entre os participantes, pois as diferenças são visíveis. Essas fronteiras são demarcadas, principalmente, entre dois grandes grupos: aqueles que vão à festa com seus carros e bons sons instalados, bebidas e amigos afins e aqueles que não têm carro e vão para curtir o que os primeiros disponibilizam, agrupando-se em volta das bebidas e nas proximidades desses carros. Entretanto, nas últimas observações de campo, pude perceber que a inserção dos grandes paredões tem possibilitado uma participação mais "unificada" desses jovens, pois é como se tivessem um grande palco só para eles, com direito a um bom som, jogo de luz e um telão. Percebo os paredões como elemento de inclusão desses jovens na festa, ou seja, não ficam mais à margem, na dependência dos sons dos carros. Esses grandes paredões têm aglomerado grandes multidões, incluindo aqueles que vão de carro, mas preferem deixá-lo estacionado, sem fazer uso do som.

As redes de sociabilidades observadas no contexto dessa festa se dão mais entre os grupos de jovens que já se conhecem, moradores do município, isso não significa a negação da existência de uma interação com os de "fora", pois a festa também propicia esse processo de interação - muitas vezes mobilizados pela paquera, interesse compartilhado por ambos. A relação é situacional e demarcada por um distanciamento e uma aproximação, uma vez que a maioria desses jovens não se conhece, portanto, são distantes em vários aspectos, mas que pelo momento 


\section{Festa na praia: turismo e sociabilidade juvenil}

de compartilhamento de interesses comuns, como a paquera, uma aproximação pode acontecer - o que pode se manter, de acordo com a relação estabelecida e a frequência desse visitante na localidade, bem como isso pode se desfazer no mesmo instante. Nesse sentido, como aponta Simmel (2006), a sociabilidade se constrói e se dissolve.

Assim, as manifestações de paquera observadas parecem ter implicado em mudanças na vida destes jovens no que diz respeito às relações afetivas. $\mathrm{O}$ contexto diverso, a aproximação com outras pessoas e eventos que dinamizam e mobilizam a cidade criam expectativas e interesses variados nos jovens. E uma parte desses, principalmente as moças, parecem ter se encantado com o "outro" (o viajante, o turista) considerado diferente do que lhe é comum no seu cotidiano, o que tem gerado algumas relações mais duradouras e matrimônios. As observações possibilitam perceber que existe uma diferença de sexo quanto à conquista de uma paquera, no sentido de que seria mais fácil para as jovens do que para os rapazes dessa localidade estabelecer esse tipo de relação com o outro de fora. Uma hipótese é a de que existiriam muito mais homens de fora do que mulheres em busca de manter uma relação com os jovens locais. Esse aspecto surgiu na pesquisa a partir da fala de alguns rapazes reclamando que suas conterrâneas estariam interessadas só nos homens de fora, principalmente estrangeiros. Tal situação estaria dificultando o desenvolvimento de uma relação afetiva entre os jovens locais, fazendo com que esses rapazes procurem fora de sua localidade outras parceiras. Assim, parece que a dinâmica das relações afetivas vem se reestruturando nessa localidade, e que ela se diferencia de acordo com o sexo, implicando também nas dimensões das relações de gênero. Tal fenômeno não é específico dessa realidade, pois acontece em outros contextos de fluxos de pessoas, imagens e dinheiro, ou seja, em locais que existem muitos intercâmbios culturais.

Atualmente existem estudos interessados em compreender essas relações sexuais e amorosas que acontecem em contextos de turismo globalizado (Piscitelli, 2010, Medeiros, 2011, dentre outros). Buscam não generalizar, mas diferenciar as relações que se denominam de "turismo sexual" (as relações de aventura e sem compromisso e, geralmente, de natureza comercial) e o turismo com ênfase romântica - o que se tem denominado de "turismo afetivo" (que se caracteriza pela intenção de viver um namoro, uma relação mais duradoura), considerando os vários interesses que fazem parte dessas relações. Essas pesquisas tentam entender também as diferenças de sexo nesses processos relacionais, pois existem lugares que tanto as mulheres como os homens locais estabelecem uma relação com o estrangeiro, embora geralmente predominem as relações entre mulheres locais e homens estrangeiros.

Portanto, nessa localidade existe um fluxo contínuo de temporadas em que as experiências urbanas se intensificam como nos períodos e festas citadas anteriormente. Momentos que muitos jovens destacam como sendo significativos, 
uma vez que a localidade fica mais movimentada, ressaltando as festas e pessoas diferentes. Para alguns, as férias de final de ano correspondem ao período que acontecem as melhores festas de Flecheiras. Entretanto, existe um sentimento ambíguo entre os jovens, pois acabam explicitando, também, que esse movimento chega a incomodar, desejando o retorno dos dias mais calmos: "Assim, tudo demais cansa, no período mesmo do réveillon, eu sinto tanta saudade de Flecheiras calma, mas tem época que fica muito tempo sem ninguém que você prefere ter movimento para se divertir, para movimentar Flecheiras, se não, não tem outras coisas" (Marina, 25 anos, entrevista cedida em janeiro de 2010). Outros jovens ressaltam a sensação deles com relação a esse movimento, afirmando que é como se eles se sentissem "estrangeiros" em sua própria comunidade: "é estranho, mas tem horas que não me sinto à vontade, me sinto observado, como se estivesse no big brother"; "tem horas que parece que não estou na minha cidade, parece outro lugar". Essa relação é muito mais intensa porque os jovens dessa localidade estão em interação não só com experiências nacionais, mas internacionais, uma vez que a presença dos estrangeiros (portugueses, italianos, espanhóis) é frequente, pois alguns residem no local.

As experiências relativas à festa do pisca nos conduzem a refletir sobre a "translocalidade" que, segundo o antropólogo Appadurai (1997), é um processo que é possível se pensar a partir desses deslocamentos geográficos contemporâneos de "desterritorialização" e "reterritorialização", assim como os locais em dinâmica de turismo. Assim, o período dessa festa produz outras experiências diferentes daquelas vividas no cotidiano da localidade, uma vez que esta é atravessada por múltiplos fluxos de pessoas, imagens, sons, estilos de vida, valores, ideias, dinheiro e tecnologia, o que implica nos modos de vida desses jovens. Nesse sentido, concordo com a seguinte ideia de Firmino da Costa: "As formas de sociabilidade inscrevem-se no núcleo em torno do qual se organizam relacionalmente e se configuram simbolicamente os estilos de vida" (Costa, 2003, p.125).

A localidade de Flecheiras tem vivenciado mudanças que legitimam novas práticas sociais e intensificam o seu processo de urbanização, configurando para as novas gerações uma história relativamente diferente daquela vivida pelas gerações mais velhas. Processo que se justifica com o litoral sendo representado como um lugar turístico, onde acontecem múltiplos fluxos de pessoas e múltiplas circulações de imagens, estilos e modos de vida urbanos. E ao mesmo tempo, essa pequena localidade litorânea aparece como o outro lado da agitação urbana, como um lugar tranquilo, uma imagem atrativa da natureza a ser contemplada e consumida pelos turistas. As interações com turistas que vêm de diferentes lugares continuam produzindo diferenças importantes entre essas zonas litorâneas como áreas de contatos de diversas culturas.

Latitude, vol. 6, n¹, pp.37-50, 2012. 
Festa na praia: turismo e sociabilidade juvenil

\section{Referenciais Bibliográficos}

APPADARUAI, Arjun. Soberania sem territorialidade: notas para uma geografia pós-nacional. Tradução do Inglês: Heloísa Buarque de Almeida. Novos Estudos Cebrap, São Paulo, 1997, nº 49, p. 33-46.

COSTA. António Firmino. Estilos de Sociabilidade In: Cordeiro, Graça Índias et al. Etnografias Urbanas. Oeiras: Celta editora, 2003.

GUARINELLO, Norberto Luiz. Festa, trabalho e cotidiano. In: JANCSÓ, István e KANTOR, Iris (Orgs). Festa: Cultura e sociabilidade na América Latina. Volume II

- São Paulo: Hucitec, Editora da Universidade de São Paulo, Fapesp, Imprensa Oficial - (Coleção Estante USP - Brasil 500 anos; v.3), 2001.

MEDEIROS, Maria da Graças Lucena de. Casais binacionais: turismo afetivo, turismo sexual e conjugalidade. In: XV Congresso Brasileiro de Sociologia, 26 a 29 de Julho de 2011, Curitiba (PR)

PAIS, Machado José. A vida como aventura: uma nova ética do lazer? In: New routes for Leisure. Actas do Congresso Mundial do Lazer/World Leisure congress. ICS: Lisboa, 1994.

Is Leisure studies "ethnocentric?" Other "musics", other insightis: A view from Lisbon, Portugal In: Wold Leisure Journal, V: 52, 2010.

PISCITELLI, Adriana. "Gringas ricas": viagens sexuais de mulheres europeias no Nordeste do Brasil. Rev. Antropol. [online]. vol.53, n.1, pp. 79-115, 2010. ISSN 00347701.

RODRIGUES. Adyr A. B. Desafios para os estudos do turismo In: Rodrigues. Adyr. B. (Org.) Turismo e Geografia: Reflexões teóricas e enfoques regionais. 3 ed. São Paulo: Hucitec, 2001.

Percalços do planejamento turístico: o Prodetur-NE In:

Rodrigues. Adyr. B. (Org) Turismo e Geografia: Reflexões teóricas e enfoques regionais. 3 ed. São Paulo: Hucitec, 2001.

ROSA. Maria Cristina. As festas e o lazer In: MARCELLINO, Nelson Carvalho (Org.) Lazer e Cultura. Campinas, SP: Alínea editora, 2007.

SIMMEL, Georg. Questões fundamentais da sociologia: indivíduo e sociedade. Tradução: Pedro Caldas. Rio de Janeiro: Jorge Zahar Ed., 2006.

Sítios virtuais consultados:

Prefeitura Municipal de Trairi. Disponível em: www.trairi.ce.gov.br. Acesso em: 08/10/09

Flecheiras. Enseada de encantos saiba mais. Disponível em:

http://diariodonordeste.globo.com/materia.asp?codigo=661131 acesso em outubro de 2011. 